\title{
Comparison of The Compressive Strength and The Microstructure of Metakaolin Metastar and Metakaolin Bangka as Additive in Ordinary Portland Cement
}

\author{
Sotya Astutiningsih ${ }^{1}$, Widyaningsih Sura', and Ahmad Zakiyuddin ${ }^{1 *}$
}

${ }^{1}$ Department of Metallurgical and Materials Engineering, Faculty of Engineering, Universitas Indonesia, Depok 16424, Indonesia

\begin{abstract}
Various This paper presents the results of the investigation on the use of Metakaolin $\left(\mathrm{Al}_{2} \mathrm{Si}_{2} \mathrm{O}_{2}\right)$ as a supplementary cementing materials to improve the strength of cement. The most effective way to increase the strength of cement is the substitution of a proportion of cement with supplementary cementing materials. One of them was Metakaolin. Metakaolin was produced by thermal treatment calcination from Kaolin at 600-800 Celcius and has highest alumina and silicate purity. By added Metakaolin to Portland Cement type I (OPC), the amount of Calcium Silicate Hydrate $(\mathrm{CSH})$ will increase through binding with Calcium Hydroxide $(\mathrm{CaOH})$. There were two kinds of Metakaolin used in this investigation, commercial metakaolin named Metakaolin Metastar compared with Metakaolin Bangka which derived from Indonesia local resources, Bangka Island. Four Metakaolin replacement levels were employed in this investigation: $5 \%, 0 \%, 15 \%$, and $20 \%$ with water per cement ratio $0.35,0.40$, and 0.50 both of Metakaolin Metastar and Metakaolin Bangka. The cement pastes cured at room temperature for 7,14 , and 28 days. The mechanical strength examined by compressive strength test, the microstructure were examined by SEM-EDS. The results of the study revealed both Metakaolin Metastar and Metakaolin Bangka enhanced the compressive strength of OPC. The most appropriate strength was obtained for a substitution of $20 \%$ metakaolin metastar which had 46,15\% higher than OPC and 5\% metakaolin Bangka which had 39,06\% higher than OPC. The hydration rate was examined by Thermal Analysis Monitor. The results indicated that metakaolin metastar released higher heat than metakaolin Bangka. It can be concluded that Metakaolin metastar was more effective than metakaolin Bangka as additive in OPC.
\end{abstract}

\section{Introduction}

Concrete is probably the most extensively used construction material in the world. It is one of the most heavily consumed substance in over two illion tonne quantities per year, by 2050, concrete use is predicted to reach four times the 1990 level. This largely due to the strength and low relative cost. [1]

Performance of concrete is determined by its mechanical properties. There are so many studies in the literature focusing on the improvement of concrete performance by replacement of Portland Cement to some extents of various mineral admixtures. The most common Supplementary Cementitious Materials (SCMs) is pozzolan that conforms to ASTM C618. [2] Pozzolan are materials that consist predominantly of silica $\left(\mathrm{SiO}_{2}\right)$ and alumina $\left(\mathrm{Al}_{2} \mathrm{O}_{3}\right)$ content tend to have higher pozzolanic capacities. Pozzolan consist of several variety like silica fume, fly ash, metakaolin, trass, blast furnace slag, etc. Pozzolan react with calcium hydroxide $(\mathrm{CH})$ established calcium silicate hydrate (CSH). Due to pozzolanic and filling effects, pozzolan are capable of enhancing the mechanical strength through increasing $\mathrm{CSH}$ content. Generally, the effects of pozzolan may be assessed as improvement in workability, durability to thermal cracking, durability to chemical attacks, and production of high performance concrete.[3-8]

Recently, there has been a growing interest in the utilization of high reactivity metakaolin $\mathrm{Al}_{2} \mathrm{Si}_{2} \mathrm{O}_{7}$ (MK). MK is an ultrafine material, the particle size generally less than $2 \mathrm{um}$, which is significantly smaller than that of cement particles, though not as fine as silica fume. MK is white in color (whereas silica fume is typically dark grey or black), making it particularly attractive in color matching and other architectural applications.[9]

*corresponding author. E-mail: zakiyuddin@metal.ui.ac.id, Tel. +62-21-7872350. 
MK differs from other SCMs, like fly ash, silica fume, and slag, in that it is not a by-product of an industrial process nor is is entirely natual; it is derived from a naturally occurring mineral and is manufactured for a specific purpose under carefully controlled conditions. Unlike by-product pozzolans, which can have variable composition, MK powders are very consistent in appearance and performance. As such a much higher degree of purity and pozzolanic reactivity can be obtained. MK has great promise as an SCM as it can improve many properties of cement while also reducing cement comsumption.[9]

MK is produced by heat-treating kaolin, one of the most abundant natural clay minerals, to temperature of $400-900^{\circ} \mathrm{C}$. This calcinations serves to break down the structure of the alumina and silicate layers becomes separated and releases the evaporated air group, out of the main structure. It continued until the aluminum and silicate that had been separately, merged into Metakaolinite formed the $\mathrm{Al}_{2} \mathrm{Si}_{2} \mathrm{O}_{7}$ compound.

The small particle size of $\mathrm{MK}$ influence the performance of cement. The ultra-fine particles of MK fill the voids in cement, which makes the microstructure of matrix denser. MK can fit between cement grains, allow for more efficient paste packing, lowers the mean size of capillary pores. In addition, acting together, many small particles have a large total surface area, leading to increase in reactivity, and surely enhanced the compressive strength.[3-4]

MK when used as a partial replacement substance for cement, it react with calcium hydroxide $\left(\mathrm{Ca}(\mathrm{OH})_{2}\right)$ one of the by-products of hydration reaction of cement and results in additional Calcium Silicate Hydrate $(\mathrm{CSH})$ which results in increased strength. However, MK also contains alumina which on reaction produces additional alumina containing phases some of which are cystalline. These include $\mathrm{C}_{4} \mathrm{AH}_{13}, \mathrm{C}_{3} \mathrm{AH}_{6}$, $\mathrm{C}_{2} \mathrm{ASH}_{8}[8]$. Recalling cement chemistry notation, the basic hydration reactions are as follows :

$$
\begin{gathered}
2 \mathrm{C}_{3} \mathrm{~S}+11 \mathrm{H} \rightarrow \mathrm{C}_{3} \mathrm{~S}_{2} \mathrm{H}_{8}+3 \mathrm{CH} \\
2 \mathrm{C}_{2} \mathrm{~S}+9 \mathrm{H} \rightarrow \mathrm{C}_{3} \mathrm{~S}_{2} \mathrm{H}_{8}+\mathrm{CH} \\
\mathrm{C}_{3} \mathrm{~A}+3 \mathrm{CSH}_{2}+26 \mathrm{H} \rightarrow \mathrm{C}_{6} \mathrm{AS}_{3} \mathrm{H}_{32} \\
2 \mathrm{C}_{3} \mathrm{~A}+\mathrm{C} 6 \mathrm{AS} 3 \mathrm{H}_{32}+4 \mathrm{H} \rightarrow 3 \mathrm{C}_{4} \mathrm{ASH} 12 \\
\mathrm{C}_{4} \mathrm{ASH}_{12}+\mathrm{SCSH}_{2}+16 \mathrm{H} \rightarrow \mathrm{C}_{6} \mathrm{AS}_{3} \mathrm{H}_{32} \\
\mathrm{MK}\left(\mathrm{Al}_{2} \mathrm{Si}_{2} \mathrm{O}_{7}\right)+\mathrm{CH}+\mathrm{H} \rightarrow \mathrm{C}-\mathrm{S}-\mathrm{H}, \mathrm{C}_{4} \mathrm{AH}_{13}, \mathrm{C}_{3} \mathrm{AH}_{6}, \\
\mathrm{C}_{2} \mathrm{ASH}_{8}
\end{gathered}
$$

In nature, $\mathrm{MK}$ can be found in various parts of the world. Fortunately, Indonesia especially Bangka and Belitung Island has a great amount of aluminosilicate mineral known as kaolin. In total, Indonesia has a number of resources amounted to 1414.69 million tons of kaolin [10]. This kaolin was used as raw material for paper, paint and porcelain which is valued at a low price. This price could be increased ten times when being commercially as metakaolin.
This investigation evaluated the potential of MK Bangka for use as supplementay cementitious materials. The influence of MK fineness is investigated and the performance of these particular MK is compared to commercial MK. Through this comparison, we aim to achieve two objectives: first to compare the mechanical and metallurgical properties of cement pastes based on the two metakaolins, and second to increase the value of kaolin Bangka commercially.

\section{Experimental}

\subsection{Material}

The materials used in this study were Ordinary Portland Cement (OPC), MK Metastar, MK Bangka, and water. OPC supplied by Indocement Tunggal Prakarsa. MK Metastar was commercial MK purchased from IMERYS, UK, the properties have been listed in Table 1. MK Bangka was obtained by calcinating milled Bangka Island kaolin at $700^{\circ} \mathrm{C}$ for 4 hours. Before calcination, kaolin has been milled with $20 \mathrm{rad}$ per minute rate for 20 minutes. The chemical composition of kaolin shown in Table 2.

MK Bangka and MK Metastar have a quite different texture. MK Bangka is dry and easy to fly while the Metastar is moist and stable. However, metakaolin Bangka is two times denser than Metastar.

Table 1. Properties of MK Metastar

\begin{tabular}{|l|l|}
\hline Test Name & Results \\
\hline Brightness \% reflectance & $86.6 \%$ reflect \\
\hline$\%$ Moisture & $0.380 \%$ \\
\hline pH @ $20 \%$ solids & $4.80 \mathrm{pH}$ \\
\hline Particle size \% <2 um & $64.4 \%$ \\
\hline Residue test using 325 screen & $0.0009 \%$ residue \\
\hline
\end{tabular}

Table 2. Properties of MK Bangka

\begin{tabular}{|l|l|l|l|l|}
\hline Composition & $\mathrm{SiO}_{2}$ & $\mathrm{Al}_{2} \mathrm{O}_{3}$ & $\mathrm{Fe}_{2} \mathrm{O}_{3}$ & $\mathbf{T i O}_{2}$ \\
\hline Weight (\%) & 47.4 & 36.8 & 0.85 & 0.41 \\
\hline Composition & $\mathbf{C a O}$ & $\mathbf{M g O}$ & $\mathrm{K}_{2} \mathrm{O}$ & $\mathbf{N a}_{2} \mathbf{O}$ \\
\hline Weight (\%) & 0.03 & 0.18 & 1.42 & 0.07 \\
\hline
\end{tabular}




\subsection{Specimen Preparation}

The pastes was cast in steel moulds of dimensions $50 \mathrm{~mm} \times 50 \mathrm{~mm} \times 50 \mathrm{~mm}$ [10] and moist cured at room temperature for periods of 7, 14, and 28 days. Substitution levels of OPC by MK chosen for the pastes cement were $5 \%, 10 \%, 15 \%$, and $20 \%$ and the water to cement ratio $(\mathrm{w} / \mathrm{c})$ used was $0.35-0.5$ depends on the proportion of substitution. In order to ensure good dispersion of the MK, amounts of MK and cement were first mixed until homogenous mixture was obtained. Then water was added slowly. The pastes was cast into $50 \mathrm{~mm}$ cube moulds which were then covered by cling film. The specimens were demoulded after 24 hours from casting and then cured under water until the desired curing times of 7, 14, and 28 days. The microstructure products of some selected pastes were characterized using SEM and EDS observation.

Table 3. Mix composition of cement pastes

\begin{tabular}{|c|c|c|c|}
\hline $\begin{array}{c}\text { Replacement } \\
\text { Levels }\end{array}$ & $\begin{array}{c}\text { W/C } \\
\text { ratio }\end{array}$ & $\begin{array}{c}\text { Cement } \\
\text { (gram) }\end{array}$ & $\begin{array}{c}\text { MK } \\
\text { (gram) }\end{array}$ \\
\hline $0 \%$ & 0.35 & 800 & 0 \\
\hline $5 \%$ & 0.35 & 760 & 40 \\
\hline $10 \%$ & 0.40 & 720 & 80 \\
\hline $15 \%$ & 0.40 & 680 & 120 \\
\hline $20 \%$ & 0.50 & 640 & 160 \\
\hline
\end{tabular}

\subsection{Testing and Analysis Method}

\subsubsection{Compressive Testing}

Compressive strength test of all specimens was prepared according to ASTM C109[14]. Compression testing machine with loading rate of $60 \mathrm{kN} / \mathrm{min}$ was used to determine the compressive strength of specimens. The mould used for compressive test was $50 \mathrm{~mm} x$ $50 \mathrm{~mm} \times 50 \mathrm{~mm}$. Each composition had three samples, the average of those was the value.

\subsubsection{SEM and EDS}

Some selected pastes were characterized using FEISEM of CMPFA FTUI. The morphological forms of fracture surface were analysed to identified the phase of hydration process and evolution of porosity. Then the picture analysed by IMEJ application to quantified the total area of porosity.

\subsubsection{Thermal Analysis}

Some selected pastes were tested for heat of hydration for seven days. The specimens were tested using TAMAIR owned by Indocement Tunggal Prakarsa company.

\section{Results and Discussion}

\subsection{Results}

\subsubsection{Compressive Strength}

The results of the compressive strength tests of OPC, OPC-MK Metastar, and OPC-MK Bangka are shown in fig.1, each value is the average of three measurements. It can be seen that the cement pastes containing MK had higher compressive strength than OPC. Secara rata-rata compressive strength of OPC is $\mathrm{x} \%$ lower than MK metastar and lower than MK Bangka. It is clear that the compressive strength of all cement pastes increases with increasing time of hydration up to 28 days. Also, it proven that by added some MK into OPC increases the compressive strength. This mainly due to the increase of the amount of hydration products such as $\mathrm{CSH}, \mathrm{CAH}$, and $\mathrm{CASH}$ and their accumulation within the available pores giving high strength.

Partial substitution with MK Metastar into OPC increased the compressive strength of cement. It showed strengths an average of $46,15 \%$ greater than OPC. At all ages, the compressive strength increased linearly with the proportion substitution of MK Metastar. It is clear that cement paste having 20\% MK Metastar gives the highest compressive strength values than those of OPC or the other proportion. This is due to reaction between MK Metastar and $\mathrm{CH}$ that produced more $\mathrm{CSH}$.

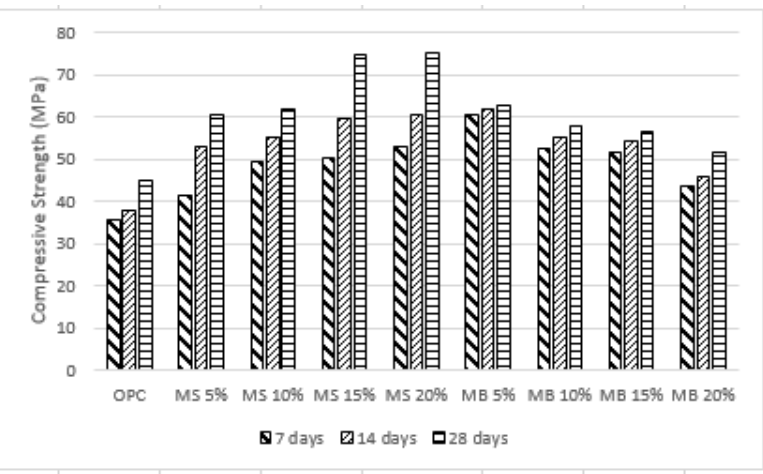

Fig. 1. The compressive strength of OPC, MK Metastar,and MK Bangka

Partial substitution with MK Bangka into OPC also increased the compressive strength of cement. It showed strengths an average of $39.6 \%$ greater than OPC. Different with MK Metastar, MK Bangka has the highest 
compressive strength with $5 \%$ substitution. This is due to an increase in the water content $(\mathrm{w} / \mathrm{c}=0.35,0.40$, and 0.50 for $5 \%, 10 \%, 15 \%$, and $20 \% \mathrm{MK}$, respectively) and to the dilution effect of the cement by MK. The MK contents were too high to allow the pozzolanic activity to counteract the dilution of the cement.[11]

\subsubsection{The morphological Observation}

Scanning electron microscopy was completed to observe the hydration product of cement paste. The hydration mechanism can be investigated through the development of the microstructure of the cement paste at different time points during the hydration process. Porosity decreases with hydration time, as more CSH is formed [3,12]. In THE following section, the microstructure evolution of blended cement made from MK metastar and MK Bangka at 7 and 14 days of hydration presented.

Fig.2 shown the effect of MK Metastar on reduction porosity of cement paste. It can be seen that the
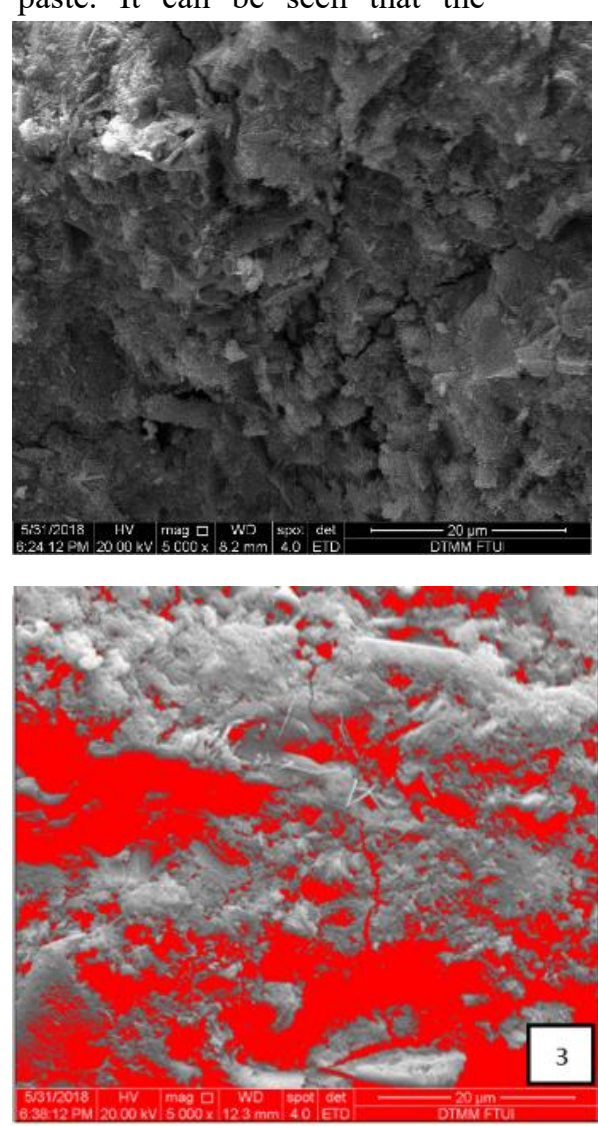

Fig. 2 The microstructure of 5\% MK Metastar at the age of 7 days (left) and 14 days (right)
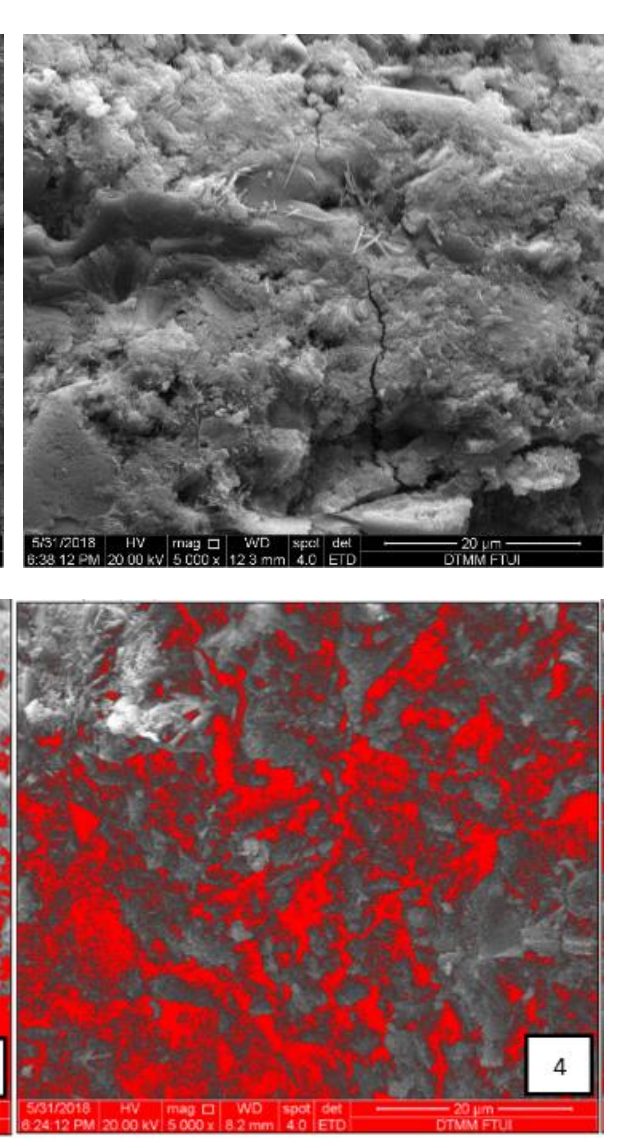

microstructure of MK Metastar at the age of 7 days has a bulk structure than 14 days. The denser microstructure indicate less porosity. This is mainly due to the particle size of MK is smaller than the particle size of cement, so it can filled the porous of cement. The less porosity signify enhacement of the strength of cement. It appropriate with the compressive strength of blended cement with MK Metastar that shown enhacement from the age of 7 days to 14 days. By using IMEJ application the porosity can be quantified as shown on fig.2. It is clear that at the age of 7 days, the total porosity is about $29.79 \%$ reduce to $27.90 \%$ at the age of 14 days.

Fig.3 shows the effect of MK Bangka on reduction porosity of OPC. Similar with the results of MK Metastar, MK Bangka also presents the reduction porosity of cement paste at the age of 7 days to 14 days. Nonetheless, it can be seen that the microstructure of MK Metastar is denser than MK Bangka. It is confirmed by analyst using IMEJ application that shown the total area porosity at the age of 7 days is about $36.33 \%$. It is wider than 14 days which has the total area porosity about $31.03 \%$.

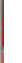




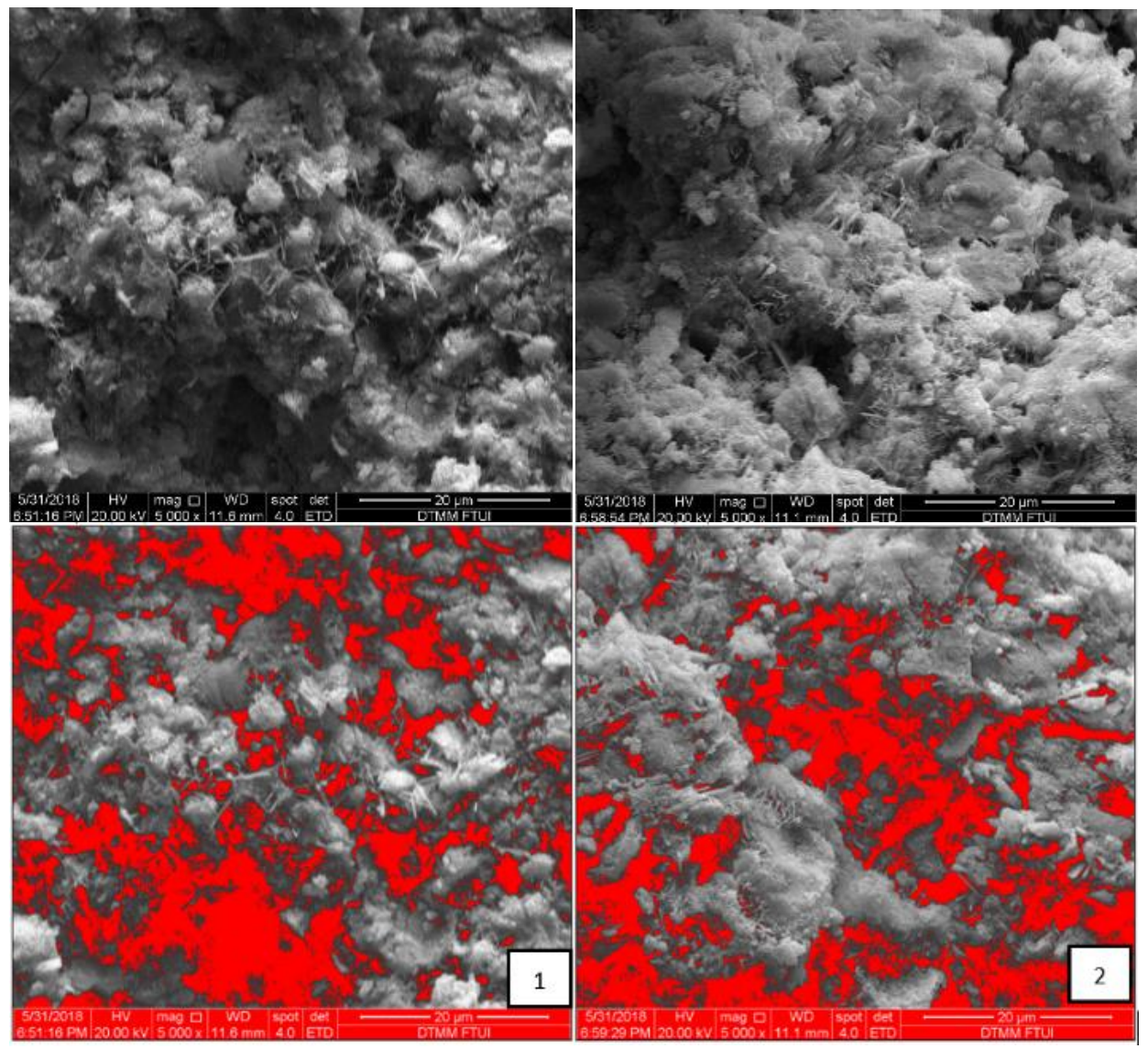

Fig. 3. The microstructure of 5\% MK Bangka at the age of 7 days (left) and 14 days (right)

\subsubsection{TAM}

TAM instrument was performed to monitor the heat flow when hydration process. Fig.4 shown that heat release of $5 \%$ and $15 \%$ of MK Metastar dan MK Bangka. Both MK have similar graphs, the maximum peak occurs at 7 hours. 5\% MK Metastar released 12,11 $\mathrm{J} /$ gh while MK Bangka released 11,31 J/gh and 15\% MK Metastar released 11,99J/gh while MK Bangka released $10,38 \mathrm{~J} / \mathrm{gh}$. It is clear that MK Metastar released more heat than MK Bangka. This is due to the finer particle of MK Metastar. According to literature the finer particle of MK, the faster the heat reaction of hydration. This is due to total surface area of MK and CASH and their accumulation within the available pores giving high strength. Coarser cements will generally produce larger interparticle spaces within the initial arrangement of cement particles in water. During hydration, these pores may persist as being larger than their counterparts in an equivalent paste prepared with a higher fineness cement, leading to larger flaw sizes and concurrently reduce reduced strengths for an equivalent amount of cement hydration (heat release). [11,13] 


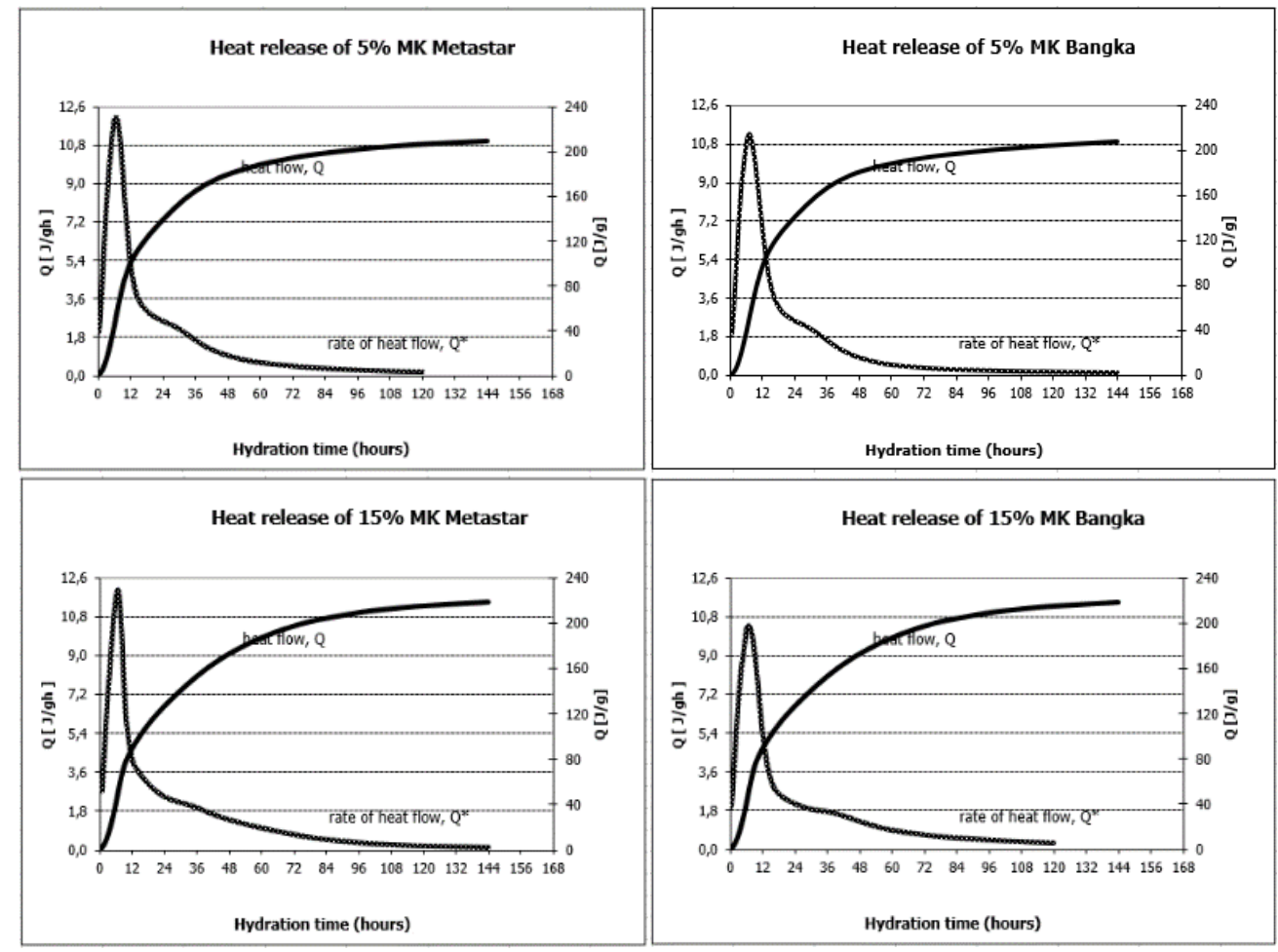

Fig. 4. The microstructure of 5\% MK Metastar at the age of 7 days (left) and 14 days (right)

\section{Conclusion}

Based on research that has been conducted on OPC with the addition of MK Metastar and MK Bangka, the following conclusions can be drawn.

1. Addition of $\mathrm{MK}$ as an additive has an effect on the strength of OPC. As seen on the results of compressive strength-test which has a better value than OPC without MK.

2. The addition of MK Bangka increase the compressive strength of OPC about $39.06 \%$ with the most optimal composition at 5\% replacement levels.

3. The addition of MK Metastar increase the compressive strength of OPC about $46.15 \%$ with the most optimal composition at $20 \%$ replacement levels.

4. The microstructure of MK Metastar has a lower total area porosity than MK Bangka.

5. The hydration reaction of OPC with addition of MK Metastar released higher heat of hydration than MK Bangka.

6. In general, MK Metastar is still more effective in enhancing the mechanical performance than MK Bangka.

\section{Acknowledgment}

This research was supported by University of Indonesia through Hibah Publikasi Internasional Terindeks untuk Tugas Akhir Mahasiswa (Hibah PITTA) program. (2535/UN2.R3.1/HKP.05.00/2018)

\section{References}

1. The Concrete Corundum. (2008). Construction, [online] pp.62-64. Available at: http://www.rsc.org/images/Construction tcm18-

\section{0.pdf}

2. ASTM C618-17, Standard Specification for Coal Fly Ash and Raw or Calcined Natural Pozzolan for Use in Concrete, ASTM International, West Conshohocken, PA, 2017, www.astm.org

3. El-Diadamony, H., Amer, A., Sokkary, T., \& ElHoseny, S. (2016). Hydration and characteristics of metakaolin pozzolanic cement pastes. HBRC Journal.

http://dx.doi.org/10.1016/j.hbrcj.2015.05.005

4. Güneyisi, E., Gesoğlu, M., \& Mermerdaş, K. (2007). Improving strength, drying shrinkage, and 
pore structure of concrete using metakaolin. Materials And Structures, 41(5), 937-949. http://dx.doi.org/10.1617/s11527-007-9296-Z

5. Dembovska, L., Bajare, D., Pundiene, I., \& Vitola, L. (2017). Effect of Pozzolanic Additives on the Strength Development of High Performance Concrete. Procedia Engineering, 172, 202-210. http://dx.doi.org/10.1016/j.proeng.2017.02.050

6. Poon, C., Lam, L., Kou, S., Wong, Y., \& Wong, R. (2001). Rate of pozzolanic reaction of metakaolin in high-performance cement pastes. Cement And Concrete Research, 31(9), 1301-1306. http://dx.doi.org/10.1016/s0008-8846(01)00581-6

7. Kim, H., Lee, S., \& Moon, H. (2007). Strength properties and durability aspects of high strength concrete using Korean metakaolin. Construction And Building Materials, 21(6), 1229-1237. http://dx.doi.org/10.1016/j.conbuildmat.2006.05.0 $\underline{07}$

8. Wild, S., Khatib, J., \& Jones, A. (1996). Relative strength, pozzolanic activity and cement hydration in superplasticised metakaolin concrete. Cement And Concrete Research, 26(10), 1537-1544. http://dx.doi.org/10.1016/0008-8846(96)00148-2

9. Justice J. (2005). Evaluation of Metakaolin for use as supplementary cementitious materials. Georgia Institute of Technology.

10.Kementrian Energi dan Sumber Daya Mineral. (2016). Executive Summary Pemutakhiran Data dan Neraca Sumber Daya Mineral Status 2016. Badan Geologi ESDM.

11.Cyr, M., Trinh, M., Husson, B., \& Casaux-Ginestet, G. (2014). Effect of cement type on metakaolin efficiency. Cement And Concrete Research, 64, 6372. doi: 10.1016/j.cemconres.2014.06.007

12.Manaf, A., \& Indrawati, V. (2011). PortlandBlended Cement with Reduced CO2using Trass Pozzolan. Journal Of The Korean
Chemical Society, 55(3), 490-494. doi: $\underline{10.5012 / \mathrm{jkcs} .2011 .55 .3 .490}$

13. Bentz, D., Barrett, T., De la Varga, I., \& Weiss, W. (2012). Relating Compressive Strength to Heat Release in Mortars. Advances In Civil Engineering Materials, $\quad 20120002 . \quad$ doi: $\underline{10.1520 / \text { acem } 20120002}$ 